Copyright (C) 2021 by Cherkas Global University

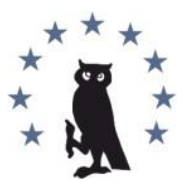

Published in the USA

Media Education (Mediaobrazovanie)

Has been issued since 2005

ISSN 1994-4160

E-ISSN 2729-8132

2021. 17(4): 715-722

DOI: $10.13187 / \mathrm{me} .2021 .4 .715$

https://me.cherkasgu.press

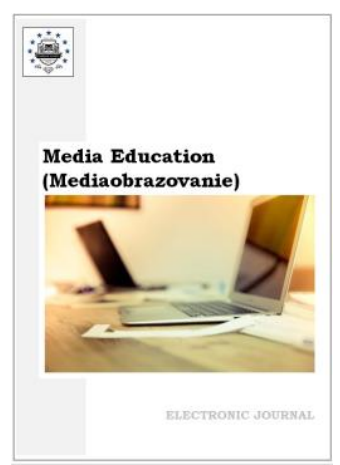

\title{
The Best Films of Soviet Film Distribution: What Were They Like for Readers of Soviet Screen Magazine (1958-1991)?
}

\author{
Marina Tselykh a, * \\ a Anton Chekhov Taganrog Institute, Russian Federation
}

\begin{abstract}
Professor Alexander Fedorov's monograph "The Best and Worst Films of Soviet Film Distribution: Opinions of the Readers of the Soviet Screen Magazine" (1958-1991) (Fedorov, 2022), along with a comparative review of the results of the audience voting, provides a broad retrospective analysis and characterization of the state of Soviet cinema of this period.

At the same time, the author proceeds not only from the changes that took place in the ideology and socio-political situation in the USSR, but also relies on objective statistical data.

The book systematizes data on the dynamics of the production of full-length feature films, the figures for the annual attendance of Soviet and foreign films per capita in the USSR, the size of the circulation of the magazine Soviet Screen, the number of readers of the magazine who participated in the annual survey, and much more.

All this allows the thoughtful reader to better understand the main guidelines that directed the audience in assessing films in different historical periods, as well as the vector of evolution of viewer preferences, expressed in the results of readers' questionnaires.

This historical and statistical approach is especially important and valuable for young viewers, as it connects the history of cinema with the history of the country, film press and film statistics.
\end{abstract}

Keywords: Soviet screen, Fedorov, book, film studies, film distribution, Soviet cinema, readers, audience.

M. Tselykh: What, in general, does the analysis of viewers' preferences carried out by the magazine Soviet Screen give today's researcher? What conclusions does this allow to draw?

A. Fedorov: Questionnaires from Soviet Screen were filled out and sent to the magazine not by millions, but by the 20,000 to 50,000 most active readers. On average this amounted to only $2 \%$ of the total circulation of the magazine, which fluctuated, but in the 1970 s and 1980 s it was about 2 million copies.

Thus, it is impossible to say that the best films of the year were voted for by ordinary viewers who watched films in cinemas in the tens of millions.

These $2 \%$ of the Soviet Screen's readership consisted of real cinephiles who went to the movies very often (often several times a week) and were generally (though of course schoolchildren also filled out the questionnaires) more educated than the average Soviet population (see the data on their level of education in the magazine). To go to the movies, but also to fill out a questionnaire, buy a stamp, and send an envelope to the editorial office, one had to be a really active fan of cinema

\footnotetext{
${ }^{*}$ Corresponding author

E-mail addresses: m.tselykh@mail.ru (M. Tselykh)
} 
and of Soviet Screen magazine. In addition, the readership of the magazine in $90 \%$ of cases lived in cities, i.e., the opinions of the rural population of the USSR were almost not taken into account.

All these (and other factors) led to the fact that the voting results of the active readers of Soviet Screen sometimes differed significantly from the box office performance of films at the box office.

Starting from 1966 Soviet Screen's editorial staff took the gender aspect of the audience into account while organizing the competition "The Best Movie of the Year", and a bit later they took into account such factors as age, education, occupation, place of residence and frequency of film viewing.

Age. Throughout all years of the surveys, the magazine's under-30 audience dominated the survey, making up over $80 \%$, often with an upward trend toward $90 \%$. About $20 \%$ of readers were underage. Readers between 30 and 40 years of age ranged from $8 \%$ to $12 \%$ with a decreasing trend. Readers between the ages of 41 and 55 were $4 \%$ to $6 \%$, and readers over 55 were $1 \%$ to $2 \%$ with a gradual decline to $1 \%$.

Education. Readers with incomplete college and higher education ranged from 30 percent to 40 percent throughout the years of the Soviet Screen surveys. In the same range fluctuated the number of readers with secondary and specialized secondary education.

Profession and study. School and college students (25\%-30 \% on average), engineers and clerks ( $25 \%-30 \%$ on average), and university students (about $15 \%)$ dominated here. Workers were about $10 \%$, pensioners $1 \%$ or less. There were very few collective farmers, usually not more than $1 \%$.

Place of residence. Over $90 \%$ of the readers of the magazine who participated in the survey lived in cities. Over $50 \%$ lived in big cities (in the 1970 s and 1980 s that figure often exceeded 70\%).

Cinema attendance. Over $90 \%$ of Soviet Screen readers surveyed went to the cinema from once a month to several times a week. At least a third of those surveyed went to the cinema every week, and every tenth went to the cinema several times a week.

The last time the editorial board of Soviet Screen published data on movie attendance of its readers who responded to a questionnaire in 1986. At the time, the majority of Soviet screen readers surveyed (93.0 \%) went to theaters from once a month to several times a week. At the same time, $30.4 \%$ went to the movies every week, and $11.3 \%$ went several times a week. In subsequent years, this kind of data was no longer published in the magazine.

Gender. Here in the results of the survey there was a significant difference between time periods. From 1966 (when the magazine first divided its readership along gender lines) to 1973, there were more than three times as many female readers as male. But then, probably, sociologists drew the editorial board's attention to the violation of gender parity, and from 1974 the situation gradually began to change. In 1974-1977, female answers to the questionnaire were only twice as many as male ones, and since 1979 the situation has stabilized at a ratio of $44 \%-45 \%$ of male votes against $54 \%-55 \%$ of female ones. Since 1974 the questionnaires that came in the mail were sorted and processed in a sample more striving for gender balance...

At the same time, of course, one must keep in mind the conventional nature of these figures for Soviet film attendance. Unfortunately, in the USSR, distortions and emendations were characteristic not only of reports on grain and cotton yields, but also of sociological research, and the science of sociology itself was in the clutches of ideological dogmatism. It often happened that the tickets sold for Fantômas, for example, were presented in official accounting documents as proceeds from Soviet cinema, especially "ideologically correct" cinema... With all that said, one can be absolutely certain that the high box office figures of Diamonds' Hand or Pirates of the Twentieth Century, if anything, were "corrected," then to a lesser extent.

In any case, the differences between the Soviet Screen questionnaires from different decades are quite significant. In the late fifties and sixties, viewers chose the best movies of the year mainly notable works of art. Foremost were S. Bondarchuk's The Fate of Man, Daneliya and Talankin's Seriozha, Chukhrai's Clear Sky, Romm's Nine Days of One Year, Kozintsev's Hamlet, Rostotsky's Let's wait until Monday...

I am convinced that this choice of the audience, apart from the artistic qualities of these films, was due in no small part to the temporary spiritual uplift that arose during the Thaw, the mass belief of viewers in the final and irrevocable overcoming of previous "mistakes" and "miscalculations", in the progressive construction of a "bright future". And although this historical and cultural period was contradictory and inconsistent, the film criticism of those years largely 
gave viewers the right artistic guidelines, supporting significant works of art, which, to a certain extent, was reflected in viewer sympathies and antipathies.

Of course, it would be naïve to view the cinema-audience relationship in a one-sided manner: the public wanted the films of A. Tarkovsky and A. German, while insidious officials imposed their hand on mass culture. Of course, captured the leadership in the 1950s - 1970s, comedy, melodrama and detective for high-ranking compilers of "thematic plan" seemed ideal in the entertainment line. For example, the concentration of the audience's feelings on the love affair had a kind of therapeutic meaning, allowing them to transfer all the negative emotions that had accumulated in real life (especially in the female half of the audience).

But didn't the viewers themselves have a craving for this kind of bright, emotional spectacle? Or don't they watch such pictures in ultra-wealthy Switzerland?

The need for strong emotions (for example, in thriller or love scenes) is inherent in viewers from the very beginning.

True, there is an opinion that the mass success of films and the success of true audience's preference are sometimes different things. They say millions will see it, but thousands will appreciate it. Or, on the contrary, it is argued that the opinion of the readers of a specialized magazine can not be the benchmark for the general situation, because not all people read the press and have such a strong desire for culture to fill out a questionnaire and send it to the editors.

This is partly true. For example, the film's lead in the Soviet Screen survey did not at all signify a similar lead in the Soviet box office, where the top places were firmly held by entertainment films. And this is logical, since as a rule the most active readers/spectators, who had seen enough of them, responded to the questionnaire about the best films of the year.

However, the overall box office statistics confirm that the evaluations by the readers of Soviet Screen are not accidental. For example, many (with a few exceptions) leaders of the Soviet box office of 1960 - 1980 s were in one way or another in the top ten or twenty best pictures according to the survey of the magazine. Thus B. Durov's Pirates of the Twentieth Century (1980), which was a box-office champion (87.6 million viewers in its first year), came in eleventh place in the magazine's questionnaire. V. Menshov's melodrama Moscow Does Not Believe in Tears (1980), which sold 84.4 million tickets, came in first place. L. Gaidai's comedies Caucasian Captive (1967) and Diamonds' Hand (1969), each with over 76 million fans, came seventh and eighth, according to readers of Soviet Screen. The operetta Wedding in Malinovka (1967) by A. Tutyshkin (74 million viewers and eighth place among the magazine readership), The Crew (1980) by A. Mitta (71 million) and Shield and Sword (1968) by V. Basov (68 million viewers), which came in second place according to reader surveys, were in the top ten distribution leaders. The same can be said of The Headless Horseman (1976) by V. Weinstock (51.7 million viewers), The Amphibian Man (1962) by V. Chebotarev and G. Kazansky (65.4 million viewers), The Dawns Are Quiet Here (1972) by S. Rostotsky (66 million viewers).

In terms of overall box office results, entertaining films were increasingly the leaders, starting from the late 1960s. And over the years the most popular genres were invariably comedies: Gentlemen of Fortune (1972) by A. Sery (65 million viewers), Ivan Vasilievich Changes His Profession (1973) by L. Gaidai (60.7 million), Afonja (1975) by G. Daneliya (62.2 million), and Office Affair (1976) by E. Ryazanov (58.4 million); adventure films, detectives: The Crown of the Russian Empire (1974) by E. Keosayan (60.7 million), The Tavern on Pyatnitskaya Street (1976) by A. Fayntsimmer (54.3 million), Petrovka, 38 (1980) by V. Grigoriev (53.4 million), Ten Negroes (1988) by S. Govorukhin (33.2 million); melodramas: Stepmother (1973) by O. Bondarev (59.4 million), Tabor Leaves in the Sky (1976) by E. Lotyanu (64.9 million), Men! (1982) by I. Babich (38.4 million), etc.

Moreover, it can also be noted that with rare exceptions (like Moscow... and The Crew) attendance of leading pictures in the 1980 s was declining along with attendance of all other films, thus confirming the established worldwide system of redistribution of youth leisure in favor of pop music, television, video, sports, the Internet (the latter, of course, came to our country in the 21st century already)...

As a result, I can conclude that the preferences of the readers/viewers of the Soviet screen, although not completely, but quite representative of the tastes of broad layers of the audience. And in terms of genre, the "box office" and "questionnaire" leaders largely coincide. 
However, there are also significant differences. Among the box-office favorites not so often there are pictures of high artistic level, but in the first prize winners of the Soviet screen a lot of genuine works of art.

But here, too, the evolution of the public's profile preferences is interesting. In the 1960 , such outstanding works as Welcome, or No Trespassing (1964) by E. Klimov, Divorce in Italian (1961) by P. Germi, with a delay published in the Russian box office Road (1954) by F. Fellini and Ashes and Diamond (1957) by A. Wajda...

From the early 1970 s the tastes of the audience, of course, began to change in a different direction: the first place in the magazine questionnaire was increasingly occupied by mediocre films in terms of art (Stepmother, Young Wife, Men!, etc.). Works of high artistic caliber began to take the lead in Soviet Screen's reader surveys much less frequently.

M. Tselykh: What kind of movie do you think the viewer needs more: movie as a work of cinema art, a film as truthful information, a comforting/romantic movie, an entertaining/adventure movie, etc?

A. Fedorov: I think there can not be any recipes here, each of the above listed varieties of cinematography had and have their own audience, and, in addition, you can simultaneously love both melodramas and detectives, enjoy both philosophical parables A. Tarkovsky, and the best Gaidai's comedies.

M. Tselykh: According to what laws does a movie affect the viewer? Poetics and aesthetics of Soviet cinema - are they understandable for the average viewer today?

A. Fedorov: N.M. Zorkaya (Zorkaya, 1981: 122-123), an eminent film scholar and culturologist, reminding readers of the folkloric origins of mass cinema, argued that:

1. "There is an absolutely real (and by no means mythical) overwhelming majority of viewers with uniform aesthetic needs, predilections, and tastes. It is that average, average viewer, or better - viewer in general, who ensures the integral mass success of a film.

2. The constants of folk taste and the archetypes of folklore perception ("fairy tale-like listening", "juggling of watching", etc.) form the basis of the integrated taste.

3. Favorites of public, hits of the Soviet film distribution are pictures where in this or that modification traditional folklore plots are reproduced, mechanisms of internal seriality work. This kind of repertoire - mass, serial production plays a role of a certain soil, a compressed "cultural layer" of centuries-old traditional images, plots, "blocks" and "tropes" of folklore genres, some of which are of ancient and most ancient origin. This repertoire is constantly replenished from above, is updated, but all entries here are transformed accordingly" (Zorkaya, 1981: 136-137).

In my books "100 most popular Soviet television movies and TV series: opinions of film critics and viewers", "One thousand and one highest-grossing Soviet film: opinions of film critics and viewers", "Record holders of the banned Soviet cinema (1951-1991) in the mirror of film criticism and viewers' opinions". "Soviet science fiction movies in the mirror of film criticism and viewers' opinions", "100 Foreign leaders of Soviet film distribution: a selected collection” (Fedorov, 2021 ; 2022) readers will find plenty of examples of viewer opinions published on the Kino-Theater. $r u$ and Kinopoisk, confirming the correctness of the typology proposed by N.M. Zorkaya. There are statements of "plausible" and "moralists", "entertained" and aesthetically oriented viewers, and, of course, in many cases the viewer's orientation toward folklore, fairy tale and mythological archetypes is evident.

Undoubtedly, the phenomenon of compensation inherent in mass culture is a natural outcome of the viewer's contact with art, making up for the missing feelings and experiences. At the same time, popular cinema is differentiated and designed for people with very different tastes. Sometimes the impact of another hit film is based on the professionalism of the director, actors, cameraman, composer, and artist, who can create a bright, attractive form of spectacle. Or a seemingly paradoxical option: the film is bad and already forgotten, but the music is so good that it continues to be played and liked by the public.

At the same time, the general trend of the audience craving for mass culture, undoubtedly, has remained in the XXI century. It is just that many viewers have moved from cinemas to home television/internet screens. 
In my opinion, the works of Soviet cinematography today remain in demand (and understandable) to a greater extent for an older audience born back in the USSR. The young audience today is more oriented toward Hollywood movies, and knows Soviet cinema mainly from entertainment films (L. Gaidai, E. Ryazanov, etc.), often shown on TV and well represented on the Internet.

M. Tselykh: What criteria do viewers use when determining the best and worst films? They are different for different audiences!? Can we talk in this case about the objectivity of the audience's assessment? What are the minimum skills a viewer needs to understand the art of cinematography, because art does not always directly declare ideas "head-on"? When does the experience of communicating with the cinema improve one's perception? What, in general, does the public need for a better understanding of cinema art?

A. Fedorov: I believe that it is possible to distinguish the following indicators/criteria in the relationship between mass audience and cinematography:

- "conceptual" (knowledge of the history and theory of cinema, specific films);

- "contact" (frequency of communication with films, the ability to navigate its flow, i.e., the choice of favorite genres, themes, etc.);

- "motivational" (emotional, gnoseological, hedonistic, moral, aesthetic motives of contact with cinema;

- "evaluative" or "interpretative" (ability to audiovisual thinking, analysis and synthesis of the spatial and temporal form of film narrative, to "identify" with the hero and author of the film, the ability to understand and evaluate the author's concept in the context of the structure of the work);

- "creative" (the level of creativity in various aspects of activity on film material, primarily in perceptual, artistic, research, practical, play, etc.).

As for the "conceptual" indicator, it is likely that without a developed level of perception and evaluation of films, the ability to empathize, and tolerance for others' opinions, the full development of an audience in the field of film art is unrealistic. In this case "film competence" turns into a caricature set of "observation", knowledge of dates, names, surnames, facts, although related to cinema, but remaining only information, at best - a source of intellectual and logical exercises, for which, as you know, a modern computer is also capable.

At the same time, the "evaluation" indicator of an audience's film competence can be formulated in more detail, according to three manifestation features - high (A), medium (B) and low (C):

- emotional involvement: a holistic (A), inaccurate (B), and non-meaningful (C) characterization of the film is given;

- emotional activity of judgment: figurativeness, vividness of speech (A), formality of judgment (B), judgment with outside help (C);

- ability to retain film images in memory (A), to retain them partially (B), superficially (C);

- ability to analyze a film: fully (A), partially (B), formally (C); images;

- imaginative thinking: free (A), partial (B), spontaneous (C) operation of film perception

- ability to communicate sufficient norms of communication with works of cinematography to make an evaluation: ability to analyze the components included in a complete evaluation of a film (A), the use of not all components (B), partial use of components (C);

- the manifestation of a value judgment about a film at a new level and in a different form: always (A), often (B), rarely (C).

It is known that science distinguishes between "primary identification," which establishes the audience's connection to the film (or other media text) as a whole, and "secondary identification with the character.

There is no doubt that the above classification is rather tentative, since in many people with a strongly pronounced "primary identification" the other levels can be found in an undeveloped, "convoluted" state. Owing to age specifics, schoolchildren, for example, as a rule, have a prevalence of the levels of "primary" and "secondary" identification. So there is no "objective assessment" of the film by a mass audience. Film critics-professionals, whose opinions on many films also often differ considerably, do not either. 
M. Tselykh: "Film watching" - what does it give an ordinary moviegoer? Is it possible to learn how to evaluate the quality of a movie based only on a large number of films watched?

A. Fedorov: Viewing itself, if it is not accompanied by a competent analysis of what has been seen, gives the viewer little in the sense of the development of his personality. Here it is necessary to develop one's own film competence, but this, of course, is a long process.

M. Tselych: Has the public always been prejudiced against emotionally heavy and multilayered semantic cinema? Don't you think that a person is generally inclined to avoid unnecessary heavy impressions and therefore prefers the happily problem-free stereotypical cinema? Hence the love for Hollywood "Happy End". Or does it simply indicate the underdevelopment of aesthetic taste?

A. Fedorov: Due to the diversity of the audience a considerable part of it has always tried to avoid emotionally heavy and multilayered movies. But the facts are stubborn: nevertheless such dramatic and far from entertaining films as The Dawns Here Are Quiet... by S. Rostotsky, Kalina Red by V. Shukshin, Young Guard and The Quiet Don by S. Gerasimov, Cold Summer of '53 by A. Proshkin, Clear Sky by G. Chukhrai, The Living and the Dead by A. Stolper, Fate of Man by S. Bondarchuk gathered in the Soviet box office from forty to sixty-six million viewers during the first year of release. Consequently, the love of the public happy end of cinematic stories (which itself, of course, is no indication of the underdevelopment of aesthetic tastes) does not exclude the mass success of dramatic works.

M. Tselykh: Please name the Soviet films that the audience preferred, and in which their authors did not give up or compromise the requirements of cinematography art.

A. Fedorov: Actually, in answering the previous question, I have already named a number of very popular Soviet very popular films, which undoubtedly belong to the works of quality art. Here you can add dozens of other films of different genres, which were included in the thousand highestgrossing Soviet films and named among the best by the readers of Soviet Screen (Ballad of a Soldier, Nine Days of One Year, The Wild Dingo Dog, Hamlet, A Boy Lives, I Step Through Moscow, Beware of the Car, I was twenty years old, Operation Y, Prisoner of the Caucasus, Diamonds' Arm, War and Peace, Republic of SHKID, Let's wait until Monday, Chronicle of the Diving Bomber, White Sun of the Desert, Moscow Does Not Believe in Tears, Autumn Marathon, The Boys, Scarecrow, Come and See, Courier, Plyumbum and many others).

M. Tselykh: Were art house film-works popular with the mass Soviet audience along with entertaining movies? What films exemplify this statement?

A. Fedorov: It depends on what is considered art house. By today's standards Ivan's Childhood by A. Tarkovsky is an art house, but in the early 1960s this picture was seen by 16.7 million viewers in the USSR. Although, of course, you won't find art house in the first hundred most popular Soviet films.

M. Tselykh: Are there any cases in the history of Soviet cinematography when the film seemed to be revived (gained a second wind) in the conditions of the new times?

A. Fedorov: Of course, there were such cases. This was the case, for instance, with a whole series of the so-called "shelf films" of the late 1960 s and 1970s which were released in the USSR in the second half of the 1980 s.

M. Tselykh: What do you think about film remakes? Can they repeat the fate of their successful predecessors, or surpass the original film in terms of artistic level and audience recognition? Isn't the filmmaker who conceives the remake doomed to biased accusations of being secondary, and, consequently, to failure? What examples can you give? 
A. Fedorov: Remakes of popular films are a common phenomenon in world cinematography. In the post-Soviet period they began to appear more and more often in our country as well. Yes, the authors of remakes are, of course, doomed to have their films compared to the originals. And this comparison, alas, they, as a rule, do not hold up. For example, in my opinion, Russian remakes of The Merry Boys, Captive of the Caucasus, and other popular Soviet films are extremely unsuccessful, to say the least.

M. Tselykh: What Soviet films of the period under consideration (1958-1991), in your opinion, occupy a significant place in the pantheon of world cinema?

A. Fedorov: It is a difficult question. If we talk about international success, it is probably Sergei Bondarchuk's War and Peace, A. Tarkovsky's films... And if we talk about the "pantheon" of Soviet cinema in Russia, then there are dozens of films, many of which I have already mentioned above.

M. Tselykh: How many Soviet films have received Oscar nominations and awards in the history of cinema development? What kind of movies are they? Is it important today for our cinema to strive for the recognition of the American Film Academy in conditions when the requirements for the films nominated for the award and the requests for the teams of their creators have changed so much?

A. Fedorov: In the feature film section such Soviet films as War and Peace by S. Bondarchuk, The Brothers Karamazov by I. Pyrev, Tchaikovsky by I. Talankin, The Dawns Here Are Quiet... and White Bim, Black Ear by S. Rostotsky, Dersu Uzala by A. Kurosawa, Moscow Does Not Believe in Tears by V. Menshov, A Private Life by Y. Raizman, Military Affair by P. Todorovsky were nominated for the Oscar in different years. War and Peace, Dersu Uzala, and "Moscow Doesn't Believe in Tears won Oscars, as you know.

As for whether it is important for our cinematography today to strive for recognition by the American Film Academy, I believe that in the current political climate Russian films have little chance of winning an Oscar. But that does not mean, of course, that these chances should not be used...

M. Tselykh: What is the fate of the most beloved Soviet films of the 1950s, 1960s, 1970s and 1980 s today?

A. Fedorov: As a rule, these films are often shown on various Russian TV channels, and they are widely available on the Internet, so that anyone can watch them at a convenient time.

M. Tselykh: How do films that did not appeal to the audience in the year of their release look like today? Are they understood by today's viewers?

A. Fedorov: It all depends on the specific audience, some people today, for example, are interested in watching M. Khutsiev's July Rain which was scolded by the Soviet official film critics and rejected by a significant part of Soviet Screen readers in the year of its release. And for some people this masterpiece of the 1960 s still seems boring and uninteresting.

M. Tselykh: What can you say about the benefits of cinema art in education of children and young people? Is it of equal standing and importance to reading? To what extent can watching films be a means of human assimilation of the surrounding world in social, moral, psychological, intellectual and other aspects? Under what conditions can watching feature films become an educational practice for viewers?

A. Fedorov: I have written extensively on the topic of film education of schoolchildren and university students and film studies (Fedorov, 1987; 1989; 2008; 2014, 2015, 2017; 2018; 2020; 2021, etc.) and continue to believe that living in a modern world oversaturated with media and being "media illiterate" is far from the best option for personal development. So I have always been and still am an advocate of film education for the younger generation. 


\section{References}

Fedorov, 1987 - Fedorov, A. (1987). "Za" i "protiv": kino i shkola ["For" and "Against": Film and School]. Moscow. [in Russian]

Fedorov, 1989 - Fedorov, A. (1989). Trudno byt' molodym: kino i shkola [It is hard to be young: Film and school]. Moscow. [in Russian]

Fedorov, 2008 - Fedorov, A. (2008). On Media Education. Moscow: ICOS UNESCO 'Information for All'.

Fedorov, 2012 - Fedorov, A. (2012). Analysis of art house media texts use during media studies in the student audience (Alain Robbe-Grillet movies case study). European Journal of Contemporary Education. 2(2): 112-123. DOI: 10.13187/ejced.2012.2.112

Fedorov, 2014 - Fedorov, A. (2014). Film studies in the university students' audience: from entertainment genres to art house. Moscow: ICO "Information for all".

Fedorov, 2015 - Fedorov, A. (2015). The application of hermeneutical analysis to research on the cold war in soviet animation media texts from the second half of the 1940s. Russian Education and Society. 57(10): 817-829.

Fedorov, 2015 - Fedorov, A. (2015). Theological media literacy education and hermeneutic analysis of Soviet audiovisual anti-religious media texts in students' classroom. European Journal of Contemporary Education. 3(13): 178-186.

Fedorov, 2016 - Fedorov, A. (2016). The Image of the White movement in the Western feature cinema (1931-2016). International Journal of Media and Information Literacy. 1(1): 11-17. DOI: 10.13187/ijmil.2016.1.11

Fedorov, 2017 - Fedorov, A. (2017). Soviet cinema in Cinema Art journal (1967). International Journal of Media and Information Literacy. 2(2): 79-89. DOI: 10.13187/ ijmil.2017.2.79

Fedorov, 2017 - Fedorov, A. (2017). The Western world in Soviet and Russian cinema (19462016). Russian Education and Society. 59(7-9): 319-464.

Fedorov, 2018 - Fedorov, A. (2018). Nazisploitation films: hermeneutic analysis. Journal of International Network Center for Fundamental and Applied Research. 5(2): 53-61.

Fedorov, 2020 - Fedorov, A. (2020). Leaders of soviet film distribution (1930-1991): trends and patterns. Media Education. 60(1): 24-62.

Fedorov, 2021 - Fedorov, A.V. (2021). 100 most popular Soviet television movies and TV series: opinions of film critics and viewers. Moscow: Information for all, $144 \mathrm{p}$. [Electronic resource]. URL: https://ifap.ru/library/book628.pdf

Fedorov, 2021 - Fedorov, A.V. (2021). One thousand and one highest-grossing Soviet film: opinions of film critics and viewers. Moscow: Information for all, $1134 \mathrm{p}$.

Fedorov, 2021 - Fedorov, A.V. (2021). Record holders of the banned Soviet cinema (1951-1991) in the mirror of film criticism and viewers' opinions. Moscow: Information for all, 102 p. [Electronic resource]. URL: https://ifap.ru/library/book625.pdf

Fedorov, 2021 - Fedorov, A.V. (2021). Soviet science fiction movies in the mirror of film criticism and viewers' opinions. Moscow: Information for all, 162 p. [Electronic resource]. URL: https://ifap.ru/library/book626.pdf

Fedorov, 2022 - Fedorov, A. (2022). The Best and the worst films of the Soviet film distribution: opinions of the readers of "Soviet Screen" magazine (1958-1991). Moscow.

Fedorov, 2022 - Fedorov, A.V. (2022). 100 Foreign leaders of Soviet film distribution: a selected collection. Moscow: Information for all, $280 \mathrm{p}$.

Fedorov et al., 2017 - Fedorov, A., Levitskaya, A., Gorbatkova, O. (2017). Directions, objectives, and author's concepts of audiovisual media interpretations of school and university in the Soviet cinema of the "stagnation" period (1969-1985). Media Education. 3: 160-184.

Fedorov, Levitskaya, 2021 - Fedorov, A., Levitskaya, A. (2021). Media manipulation and movies. Media Education. 17(1): 64-69. DOI: 10.13187/me.2021.1.64

Levitskaya, Fedorov, 2020 - Levitskaya, A., Fedorov, A. (2020). Analysis of manipulative media texts: world media literacy education experience. Media Education. 60(3): 430-442.

Zorkaya, 1981 - Zorkaya, N.M. (1981). Unique and replicated: media and reproduced art. Moscow: Art, $167 \mathrm{p}$. 